SOCIAL RESEARCH REPORTS

ISSN: 2066-6861 (print), ISSN: 2067-5941 (electronic)

THE RELATIONSHIP BETWEEN FORGIVENESS AND MARITAL SATISFACTION WITHIN COUPLES

\author{
Maria Veridiana GHIURCA, Mona VINTILA
}

Social Research Reports, 2019, Vol. 11, Issue 1, pp. 26-34

The online version of this article can be found at:

www. researchreports.ro

https://doi.org/10.33788/srr11.1.2

Published by:

Expert Projects Publishing House

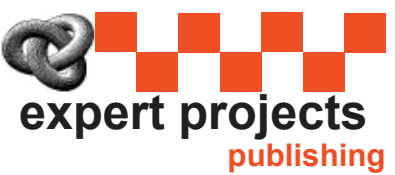

Covered by Index Copernicus International

www.indexcopernicus.com

Directory of Open Access Journals

www.doaj.org

On behalf of:

Center for Program and Social Development

Aditional services and information about Social Research Reports

can be found at:

www.researchreports.ro 


\title{
THE RELATIONSHIP BETWEEN FORGIVENESS AND MARITAL SATISFACTION WITHIN COUPLES
}

\author{
Maria Veridiana GHIURCA ${ }^{1}$, Mona VINTILA ${ }^{2}$
}

\begin{abstract}
Very often between couples, forgiveness is identified as a strong predictor of relationship satisfaction. In the present study, we include preliminary data from 31 independent field studies that focus on forgiveness and its influence on the marital satisfaction. The aim of this paper is to analyse the role of forgiveness and its relationship with marital satisfaction. As the link between forgiveness and marital satisfaction has been assessed before, this study proposes to extend the existing examinations, expand the period of studies included, and also to increase the number of population considered. Data from 31 independent studies were collected and the results show a positive and significant correlation and between this factor and marital satisfaction.
\end{abstract} ples.

Keywords: forgiveness, marital satisfaction, relationship, forgiveness in cou-

\section{Introduction}

Marital relationships are defined as the relationships between two people who have an emotional or romantic relationship, a sexual relationship, live together, are identified publicly, and identify themselves as a couple (Constantin, 2004). These relationships can simultaneously be perceived as two competitive marriage prospects, namely a source of happiness, satisfaction, gratification, and a source of frustration, restrictions, basically an obstacle in personal development and progress (Waite \& Gallagher, 2000). Each of the outlooks is relevant in its own way and reflects certain aspects of personal truth that has been attained in their own personal experience.

When people ask themselves about the establishment of a marriage or reside in this form of cohabitation, they often wonder whether marriage or divorce will make them happier. Surprisingly, evidence from social science studies generally tends to strengthen the idea that marriage seems to be an important path towards

\footnotetext{
${ }^{1}$ West University Timisoara, Timisoara. ROMANIA: E-mail: maria.ghiurca90@e-uvt.ro

${ }^{2}$ West University Timisoara, Timisoara. ROMANIA: E-mail: mona.vintila@e-uvt.ro
} 
more intense mental and emotional health, towards psychological well-being. Linda Waite and Maggie Gallagher (2000) came to the same conclusion, their explanation emphasizing the intentional nature of marriage and the social support enjoyed by married couples from others (Waite and Gallagher, 2000).

In real life, we meet both married couples with a rewarding life as well as unhappy couples. Knox and Schacht (2010) started analysing this topic of great interest to a wide audience, by clarifying how marital success can be measured through constructs called stability and marital happiness. In the authors' view, stability refers to the duration of the marital relationship as well as the partners' perception of the continuity of the relationship, while marital happiness involves more subjective aspects. Marital success is often measured by asking spouses how happy they are, how often they spend their free time together, how much the partner enjoys each others' company, how often they agree on various discussion topics, how much they are willing to solve their conflicting situations, how satisfied they are with their sexual life, how often they have taken into account the idea of separation or divorce (Gotea, 2014). Marital satisfaction was defined by Lewis and Spanier (1979) as the congruence between the expectations of one of the partners and the behaviour of the other, underlining its interpersonal dimension.

Regarding the term marital satisfaction, or even used as a synonym, other notions can be mentioned such as: marital adjustment, marital quality, marital stability. But a deeper analysis of these concepts reveals the differences between them. Satisfaction and marital happiness are purely subjective realities, lived and felt by each individual differently (Iluț, 2005). The study of this aspect of the couple's life has serious limitations because, on the one hand, we have access to these self-assessments of the quality of the relationship through individual statements subjected to the emotional state of the moment, and on the other hand, the effect of social desirability in the answers to such questions.

Social scientists have extensively investigated aspects of couple life, trying to identify the factors that influence marital satisfaction. Different authors have encountered longer or shorter, more detailed or concise lists, some incomplete, open and sometimes unstructured by such factors. Such an example is a synthesis of the characteristics of specific stable couples that have a happy relationship belonging to Konx and Schacht (2010), which contains twelve elements. In the present study we will not approach every element, but we will confine ourselves to analysing forgiveness in relation to marital satisfaction.

\section{Preliminary considerations in the relationship be- tween forgiveness and marital satisfaction}

In European culture, as a rule, people remember that forgiving means the desire to reconcile with the one who caused the offense, empathize with them, forget or ignore the harm suffered, accept it, and try to go further, whereas a small part of the general population is convinced that forgiveness means feeling affection and understanding again for the one who offended you. To this, field experts add another important aspect, namely the goodwill towards the aggressor (Paleari \& 
Pelucchi, 2013).

Forgiveness within the couple has been identified as an element that plays an important role in marital satisfaction, although forgiveness is often omitted from the list of possible interventions to increase marital satisfaction (Aalgaard, Bolen \& Nugent, 2016). Exploring relationships that are compromised by interpersonal conflicts and transgressions offers opportunities to examine forgiveness as an effective component for increasing relational satisfaction. Paleari, Regalia, and Fincham (2009) have described three ways in which people forgive others. Offense forgiveness is a specific act of forgiveness for a specific offense within a defined interpersonal framework. Dyadic forgiveness is the inclination to forgive the partner for numerous offenses. Trait forgiveness refers to the understanding of a person who tends to forgive people for offenses in multiple circumstances, including interpersonal situations involving a variety of relationships. Despite the fact that forgiveness is a derivative process, Maio, Thomas, Fincham and Carnelley (2008) note that the process of forgiving consciously incorporates the tendency to move away from negative thoughts, feelings and behaviours towards the transgressor, pointing to positive thoughts, feelings and behaviours.

Considering the various contexts in which forgiveness takes place, Gordon, Burton, and Porter (2004) explored whether the notion of forgiveness among women who are confronted with domestic violence is truly forgiveness or conscious rationalization to help them go far away. Their results showed that the more women interpreted the partner's behaviour less badly or intentionally, the more likely they were willing to forgive their behaviour and to consider continuing the relationship. Since forgiveness should never be used to excuse harmful or violent behaviour, therapists can identify certain moments in couples' therapy to explore partners' behaviours and to suggest answers to help them maintain their safety.

If forgiveness can however, provide longevity, survival, and wound healing in relationships, then it is justified to add this component to the list of key elements that help couples increase their satisfaction in relationship and maintain marriage. In other studies, forgiveness is perceived as a component of marital interventions implemented in the context of infidelity, forgiveness being conceived as a cornerstone of the successful relationship (Baucom, Gordon, Snyder, Atkins, \& Christensen, 2006).

\section{Forgiveness and marital satisfaction}

In a couple, forgiveness is identified as a powerful predictor of relational satisfaction. The study initiated by Berry and Worthington (2001) confirmed that anger as a personality trait and forgiveness as a mood, constituted predictive factors for the quality of close relationships, impacting the mental and physical health of individuals (Berry \& Worthington, 2001; Thoresen, Harris, \& Luskin, 2000).

More recently, Braithwaite, Selby and Fincham (2011) studied the path mediation mechanisms between forgiveness as a feature and relational satisfaction. They conceptualized forgiveness not only as a process that leads to a reduction in negative responses, but also as a goodwill to the transgressor. They also considered some possible mediators between forgiveness and relationship satisfaction, especially interpersonal conflict and self-regulation. Among the most important 
tactics of the interpersonal conflict were positive communication, negative communication, and physical aggression. The authors have advanced the hypothesis that relationship satisfaction has been enhanced by efforts in the relationship aimed at reducing conflict situations.

Gordon, Hughes, Tomcik, Dixon and Litzinger (2009) examined the role of forgiveness in marital satisfaction and family functioning through the use of a cross-sectional study that was conducted as part of a larger longitudinal study on family relational functioning. Emphasis has been placed on devastating relational conflicts, such as infidelities, major lies, drastic unilateral financial decisions and other similar humiliations and betrayal, which often have long-term negative effects on marital functioning (Aalgaard, Bolen \& Nugent, 2016).

Forgiveness was conceptualized in the form of two constructs: negative and positive forgiveness. The negative forgiveness is defined by grudging, withdrawal or avoidance, as well as the desire for revenge or punishment towards the betraying partner. Positive forgiveness (was) is defined as the willingness to forgive, increased empathy, greater dyadical confidence, and anger. Both negative and positive forgiveness have been examined for their impact on couples' relationships and for their effect on both dyadic and family functioning (Gordon et al., 2009).

Even though there are many kinds of forgiveness (group forgiveness or self-forgiveness), the most important part of the studies focuses on interpersonal forgiveness, that is, forgiveness between two persons, between the victim and the offender. Given the specificity of the two forms of forgiveness, for further exploration we will refer to other studies (Regalia, Paleari, 2008,; Regalia, Pelucchi, Paleari, 2010; Paleari and Pelucchi, 2013), in the present study only interpersonal forgiveness will be analysed. Recent studies also agree to assert that forgiveness is a process (that is) distinguishable from other similar phenomena such as excuse, justification, forgetfulness or reconciliation (Paleari and Pelucchi, 2013).

Gordon et al. (2009) hypothesized that couples' self-portrait of satisfaction in relationship would increase, all the more as the positive forgiveness would increase and the negative forgiveness would diminish in the relationship. Going beyond the couple's intimate relationship, the study posits the hypothesis that the parental alliance will become stronger when more positive forgiveness is experienced.

\section{Results}

Several studies have approached the relationship between forgiveness and marital satisfaction (Walrond-Skinner, 1998; Bugay, 2014; Braithwaite, Selby \& Fincham, 2011). Thus, Aalgaard, Bolen \& Nugent (2016) examined the role of forgiveness as a beneficial intervention that would favour partner satisfaction in couples therapy. In their study, they concluded that forgiveness offers a way to cope with the partner's infidelity and is related to a positive outcome in terms of relationship quality and marital satisfaction.

Braithwaite and colleagues (2011) found that forgiveness seems to be short-circuiting the use of negative conflict strategies thus allowing the couple to come out of the cycle of negative reciprocity that leads to relational distress. They have 
shown that efforts to forgive in the relationship significantly improve the relationship of marriage and marital satisfaction. They have also come to the conclusion that forgiveness is more beneficial to healthy couples than to those with big problems or those who suffer from a strong relational distress. Finally, they have shown that the tendency to forgive a partner in a romantic relationship increases the satisfaction of the relationship, through increased relational efforts and a low presence of negative conflicts.

Berry \& Worthington's (2001) study confirmed that the anger trait and the predisposition of personality forgiveness predicted the quality of close relationships with an impact on a person's mental and physical health. The research results supported the hypothesis that individuals who are prone to forgiveness have a better quality of their romantic relationship. They also concluded that the two personality traits of being forgiving or unforgiving are predictors of physical and mental health, namely, the health of a person is positively correlated with a better quality of close relationships and the presence of forgiveness as a feature of personality.

McNulty (2008) hypothesized that forgiveness could have long-term costs and found that husbands who reported that they were more forgiving were happier in the couple, had fewer severe problems, and were behaved less negatively. In time, however, wives have become far less satisfied with their marriages. Over the time the results showed that wives perceived relationship issues as more severe, while husbands perceived that relationship issues had not changed significantly. In this study, sex has influenced the relationship's satisfaction. The results of the McNulty's study (2008) showed that the increased forgiveness of spouses for partners who committed themselves to negative behaviour was beneficial in time, but less forgiveness or lack of it was detrimental to the relationship. For married couples with partners who have often adopted negative behaviours without reducing them, increased forgiveness has become detrimental to the relationship, and the quality of the relationship has deteriorated over time. Conversely, lowering forgiveness for those who have frequently adopted negative behaviour has been beneficial over time. Finally, relatively healthy marriages have experienced more positive benefits from the effects of forgiveness than troubled relationships. McNulty also suggested that an intervention that includes forgiveness could help bring stability to relations for benevolent partners over time.

Gordon, Hughes, Tomcik, Dixon \& Litzingher (2009) examined the role of forgiveness in marital and family functioning using a transversal study. Gordon et al. (2009) found that both husbands and wives reported that greater negative forgiveness resulted in the perception of lower marriage satisfaction. Subjects' perception of their relationship remained the same in assessing marital conflicts and dyadical confidence variables. The husbands and wives who reported greater positive forgiveness predicted a perception of the highest qualities of the parental relationship. In addition, greater spouse's positive forgiveness predicted positive perception of greater dyadic confidence, while greater negative husbands' and wives' forgiveness predicted increased behavioural relationships with conflict and lower levels of dyadic trust.

Forgiveness was also approached from the perspective of family therapy to help couples in cases of infidelity of one of the spouses (Olmstead et al., 2009; Woldarsky-Meneses \& Greenberg, 2014). The study conducted by Olmstead et al. (2009) 
showed there are several factors that mediate the relationship between forgiveness and marital satisfaction, namely: time, psychological education, clarification of the situation, shared acceptance of responsibility and mutual language. They also indicated that forgiveness is a sequential process and that "treating infidelity" with forgiveness influences significantly relational satisfaction.

Other studies have examined the forgiveness and quality of the couple relationship within the dyadic perspective (Arya \& Kaushik, 2015). The results of this study indicated that if the partners have resentment to one another or avoid forgiving each other; this is negatively correlated with relational satisfaction, while goodwill and openness to forgive have been correlated with marital satisfaction. The study confirmed a strong correlation between forgiveness and marital satisfaction.

\section{Conclusions}

After carefully analysing the literature, the conclusions of this paper on the phenomenon of forgiveness and its influence on marital satisfaction in the couple's relationships are directed to the fact that there is no general consensus on the use of the term forgiveness and that of marital satisfaction. Then, even if the phenomenon of forgiveness is conceptualized somewhat in a similar way, there are also several divisions or more types of forgiveness. Moreover, it has been observed that there are few empirical studies in the literature that support the validity of these concepts.

Following the analysis several articles in the literature, we can notice an important positive relationship between the phenomenon of forgiveness and marital satisfaction in the relationship between spouses in the couple. Thus, the assessed studies confirmed the hypothesis of a strong positive correlation between the phenomenon of forgiveness and marital satisfaction, both in terms of self-forgiving and that of partner forgiveness in the couple. In this regard, people who have given importance to forgiveness within the couple have experienced greater marital satisfaction along with the reduction of negative symptoms (decreased depression or better health and cardiovascular functioning). At the same time, it was found that forgiveness was beneficial for healthy relationships rather than for those with problems, and that forgiveness plays a more important role in married couples than in unmarried couples compared to marital satisfaction. Finally, the analysis of the articles in this study has been useful to me both for a better definition and operationalization of terms, as well as for confirming the initial assumptions and the organization of my own research.

The investigations have also shown the usefulness of correlative exploratory research to highlight the phenomenon of forgiveness in relation to marital satisfaction. The data obtained from this study give rise to an increase of interest in the role of forgiveness within the couple, also considering the benefits it can bring both in the short and long term, with particular emphasis on combined part of the professionals in the field. It is important to have training programs designed to prevent and manage conflict situations or transgressions, respectively to use the 
most effective strategies. The results highlight arguments regarding the importance of counselling and couples therapy, with a positive impact on the prevention of dysfunctional effects of couples' transgressions as well as intervention.

Attitudes about life events vary from an individual to another, and this could be caused by a lack of health information, a low socio-economic level (Vintila et al., 2009), lower level of personal development or a lack of social support. Social support is considerd a protective factor that can reduce the effect of stressful, overwhelming life events (Tudorel \& Vintila, 2018). These life events are own, subjective experiences they depend not only on environmental factors but also on the individual (Tudorel, Macsinga, \& Virga, 2013).

\section{References}

Aalgaard, A.R., Bolen, M.R., Nugent, R.V., (2016). A literature review of forgiveness as a beneficial intervention to increase relationship satisfaction in couples therapy. Journal of Human Behavior in the social environment, 26(1), 46-55.

APA (2011). PsycINFO - American Psychological Association, http:www.apa.org/pubs/ databases/psychinfo/index.aspx.

Arafani, A. (2017). Promoting the forgiveness in premarital counseling as a way to get a successful marriage. The International Journal of Counseling and Education, 2(1), 1-5.

Arya, B., \& Kaushik, N. (2015). Forgiveness and relationship quality: A dyadic perspective. Indian Journal of Health and Wellbeing, 6(1), 57-61.

Baucom, D.H., Gordon, K.C., Snyder, D.K., Atkins, D.C. \& Christensen, A. (2006). Treating Affair Couples: Clinical Considerations and Initial Findings. Journal of Cognitive Psychotherapy, 20(4), 375-392.

Berry, J.W. and Worthington, E.L., Jr. (2001). Forgiveness, relationship quality, stress while imagining relationship events, and physical and mental health. Journal of Counseling Psychology, 48, 447-455.

Braithwaite, R.S., Selby, E.A., Fincham, F.D. (2011). Forgiveness and Relationship Satisfaction: Mediating Mechanisms. Journal of Family Psychology, 25(4), 551-559.

Brannan, D., Davis, A., Biswas-Diener, R. (2016). The Science of Forgiveness: Examining the Influence of Forgiveness on Mental Health. Encyclopedia of Mental Health, 2, 252-257.

Bugay, A. (2014). Measuring the differences in pairs' marital forgiveness scores: construct validity and links with relationship satisfaction. Psychological Reports: Relationships \& Communications, 114(2), 479-490.

Constantin, T. (2004). Evaluarea psihologica a personalului, Iasi: Polirom.

DiBlasio, A.F. (2010). Christ-like Forgiveness in Marital Counseling: A Clinical Follow-up of Two Empirical Studies. Journal of Psychology and Christianity, 29(4), 291-300.

Fincham, F. D. (2000). The kiss of the porcupines: From attributing responsibility to forgiving. Personal Relationships, 7, 1-23.

Goian, C. (ed.) (2013). Teaching social work practice. Bucuresti: Pro Universitaria.

Gordon, K.C., Burton, S., \& Porter, L. (2004). Predicting the intentions of women in domestic violence shelters to return to partners: does forgiveness play a role? Journal 
of Family Psychology, 18(2), 331-338.

Gotea, M. (2014). Reţeaua sociala si conflictul marital constrângeri si oportunitaţi, Cluj Napoca: Presa Universitara Clujeana.

Hughes, F.M., Tomcik, N.D., Dixon, L. J., \& Litzinger, S. C. (2009). Widening spheres of impact: The role of forgiveness in marital and family functioning. Journal of Family Psychology, 23(1), 1-13.

Ilu, P. (2005). Sociopsihologia şi antropologia familiei, Iasi: Polirom.

Kachadourian, K.L., Fincham, F., Davila, J. (2004). The tendency to forgive in dating and married couples: The role of attachment and relationship satisfaction. Personal Relationships, 11(3) 373-393

Knox, D. \& Schacht, C. (2010). Choices in Relationships: An Introduction to Marriage and the Family. Tenth Edition, Belmont: Wadsworth Cengage Learning.

Lewis, R.A., \& Spanier, G.B. (1979). Theorizing about the quality and stability of marriage. În Burr, W.R. (ed.) Contemporary theories about the family: research-based theories, New York: Free Press.

Maio, G.R., Thomas, G., Fincham, F.D. \& Carnelley, K.B. (2008). Unraveling the role of forgiveness in family relationships. Journal of Personality and SocialPsychology, 94(2), 307-319.

McNulty, J.K. (2008). Forgiveness in marriage: putting the benefits into context. Journal of Family Psychology, 22(1), 171-175.

Olmstead, B.S., Blick, R.W., Mills, L.I. (2009). Helping Couples Work toward the Forgiveness of Marital Infidelity: Therapists' Perspectives. The American Journal of Family Therapy, 37(1), 48-66.

Paleari, F. G., Regalia, C., \& Fincham, F. D. (2005). Marital quality, forgiveness, empathy, and rumination: A longitudinal analysis. Personality and Social Psychology Bulletin, 31, 368-378.

Paleari, F.G., Pelucchi, S. (2013). La ricerca psicosociale sul perdono interpersonale tra un passato recente e possibili sviluppi futuri. In Barcaccia Barbar, B. B., Mancin Francesc, M. F. (ed.), Teoria e clinica del perdono, Cortina, Milano, pp. 17-58.

Paleari, G.F., Regalia, C., Fincham, F.D. (2009). Forgiveness and Conflict Resolution in Close Relationships: Within and Cross Partner Effects. Universitas Psychologica, 9(1), 35-56.

Paleari, G.F., Regalia, C., Fincham, F.D. (2011). Inequity in Forgiveness: Implications for Personal and Relational Well-Being. Journal of Social and Clinical Psychology, 30(3), 297-324.

Pelucchi, S., Paleari, G. F., Regalia, C., Fincham, D. F., (2015). Self-forgiveness in romantic relationships: 2. Impact on interpersonal forgiveness. Family Science, 6(1), 181-190.

Thoresen, C.E., Harris, A.H.S. and Luskin, F. (2000). Forgiveness and health: an unanswered question. In: McCullough, M.E., Pargament, K.I. and Thoresen, C.E. (Eds.), Forgiveness: Theory, Research, and Practice, New York: Guilford Press, pp. 254-280.

Tudorel, O. I., Macsinga, I., Virga, D. (2013). Actualizarea de sine: de la starea de bine la viziunea asupra lumii. Romanian Journal of Applied Psychology, 15(1), 20-26;

Tudorel, O. I., Vintila, M. (2018). The role of Social Support on Internet Addiction. Revista de Asistenta Sociala, 1. 
Vintila, M., Marklinder, I., Nydahl, M., Istrat, D., \& Kuglis, A. (2009). Health awareness and behaviour of the elderly: between needs and reality. A comparative study. Revista de Psihologie Aplicata, 11(2), 81-87;

Waite, L.J. \& Gallagher, M. (2000). The case for marriage: WhyMarriedPeopleAreHappier, Healthier, andBetteroffFinancially, New York: Doubleday.

Waldron, V. R., Kelley, D, L. (2005). Forgiving communication as a response to relational transgressions. Journal of Social and Personal Relationships, 22(6), 723742.

Walrond-Skinner, S. (1998). The function and role of forgiveness in working with couples and families: clearing the ground. Journal of Family Therapy, 20(1), 3-20.

Woldarsky-Meneses, C., \& Greenberg, L.S. (2011). The construction of a model of the process of couples' forgiveness in emotion-focused therapy for couples. Journal of Marital and Family Therapy, 37(4), 491-502.

Woldarsky-Meneses, C., \& Greenberg, L.S. (2014). Interpersonal forgiveness in emotion focused Couples' therapy: relating process to outcome. Journal of Marital and Family Therapy, 40(1), 49-67.

Younger, W.J., Piferi, R.L., Jobe, R.L., Lawler, A.K. (2004). Dimensions of forgiveness: The views of laypersons. Journal of Social and Personal Relationships, 21(6), $837-855$.

Zuccarini, D., Johnson, S.M., Dalgleish., Makinen, J.A. (2013). Forgiveness and reconciliation in emotionally focused therapy for couples: the client change process and therapist interventions. Journal of Marital and Family Therapy, 39(2), 148-162. 